\title{
Editorial
}

Copyright (C) All rights are reserved by Vince Quevedo

\section{Fashion is Big Business}

\author{
Vince Quevedo* \\ Kent State University, USA
}

*Corresponding author: Vince Quevedo, Associate Professor, Shannon Rogers and Jerry Silverman School of Fashion Design and Merchandising, Kent State University, USA.

Received Date: January 29, 2020

Published Date: February 03, 2020

\section{Editorial}

Although art has had a long history of struggling for acceptance as a viable and important discipline, many of its naysayers have concluded that the basic "Reading, Writing and Arithmetic" courses must take precedence in preparing students for the modern workforce. While studies have confirmed that art contributes to comprehension, retention of knowledge and greater understanding, critics have unsuccessfully waived provisions confirming the importance of the arts along with basic curriculum. Fashion equally strives to be understood, its history with home economics in post-education have forced themselves from the shame it created itself during the women's movement as a course of study to help women stay subservient to their counterpart. This distance created Home Economic departments to change their name or disband altogether. Fashion has experienced the same fate in most colleges and universities due to the public's belief that it is a waste of money to support an unimportant subject matter that can be learned in the streets such as sex prior to sex education now called Human Behavior, cooking is now Culinary Arts, and Fashion is Apparel Technology and Textiles. These changes were made to appease administrators to react towards a growing demand for the revitalized home economics topics and to find its place again in academe for profit more so than a qualified area of study.

We are facing a multitude of inquiries to satisfy new challenges from technology and industry. The challenge to decrease manpower while increasing the bottom line is the driving force to minimize production cost. While technology dominates our manufacturing sector, history is repeating itself to redefine, reinvent and rename who we are as a workforce. The Europeans have done a better job of defining and sorting out the fashion designer role. But because the job market and merchandising in the United States has steadily increased its product development role within the market, it has infringed some of the duties and responsibilities of designers to retail merchandisers hence, forcing what we once thought traditional fashion designers did.
When it comes to fashion design education in the United States, we have somewhat convinced ourselves that with a few more classes in clothing construction and fashion drawing, our merchandisers can quickly become designers by calling themselves "Product Developers" and vice versa with fashion design students. While we may be selling a larger share of the ready-to-wear market, are we truly "designing"? It begs us to ask ourselves if the most affordable clothes measure the success of design, then have we started the death of fashion design as we know it? Yes, beautifully designed clothes must sell for it to be considered a consumer-able item. But to what extent of its sales ability can be counted before it's not considered "design"? Art has often been placed in this same situation. The rarer the art is; then the more it's considered "Art". But when it becomes readily available for anyone to own, then it's not art anymore! Does this define the height of hypocrisy? Art itself has hierarchy within its own discipline. From high art to crafts, there are struggles within art programs whether to include lower arts such as crafts in their college. But there is enough interest in crafts that attract plenty of students to affect high enrollments from other majors. Financial profits seem to support maintaining and/or establishing new courses, minors or majors. For whatever reasons universities and colleges determine art's objectives are, the main reasons for keeping it are usually financial or public/donor support. Fashion is in a more precarious position. Is it art or is it a business? This conundrum puzzles the public as it does university administration. Art schools have no idea where fashion fits. Business colleges are much more accepting of fashion merchandising but is not so convinced fashion design is appropriate for the program. What most don't understand is fashion is big business. The Joint Economic Committee of the United States Congress in 2015 recorded $\$ 1.2$ trillion globally while producing $\$ 250$ billion in the United States annually. The fashion industry hires an average of 2 million people from various stages of education. The fashion designer who seems to be the center of creating fashion earned an average of $\$ 76,000$ annually in 2013. Today, fashion designers are 
becoming stars within the industry as well as the public. There are even people who are not designers but know fashion that use social media forecasting their style for others to imitate. Along with their predictions, they help to advertise certain designers and labels they follow helping companies grow their bottom line.

Branding has become another factor in redefining the fashion industry workforce and products. Similarly, to art, a famous painting by Renoir may repackage itself into special edition prints produced to cap at a certain number to be sold. In fashion, haute couture dresses in silk costing $\$ 20,000$ is copied and sold in stores for the masses for $\$ 100$. Our customers have changed. Finding the best deal for the cost is their shopping motive. This is one of many reasons "Dollar" stores increased in large numbers in the United States. All kinds of merchandise sold at $\$ 1$ replaced those costing five times more. The recession of 2009 forced many Americans to reconsider the way they looked at their shopping habits.

Textile development has certainly made an impact on commerce. In fashion, textile expansion to new discoveries influence an improved appearance, performance and longevity of today's clothes. The collaboration of textile science alongside technology has generated innovative approaches to rethinking production, manufacturing, marketing, and retail practices. It's important for textile scientists and engineers to understand the demands of today's fashion market and to focus on end users of their developments.

Fashion is business. It's big business! Whether fashion education find their home in the business or art colleges, fashion is a commerce that rival other industries when it comes to creating jobs all over the world. Fashion is a language that comes in many dialects and from many cultures. The diversity it assists in making it multi-cultural help to generate a continuing effort in building a better society. Understanding that fashion is a commodity most people in the world accept as a necessity, those of us in the fashion and textile industry must broaden our own ideals to help facilitate the affect we have in the world.

\section{Acknowledgement}

None.

\section{Conflict of Interest}

Authors declare no conflict of interest. 